\title{
Impact of Nutritional Labeling on Consumer Buying Behavior
}

\author{
P.H.K.Prathiraja and A.Ariyawardana*
}

\begin{abstract}
Nutritional label plays an important role in providing the relevant nutrition information to consumers. Inclusion of a nutritional label on food items may be an important packaging decision for the Sri Lankan food processors. Hence, a study was conducted with a view of identifying the market for nutritional labeling and the factors that influence the consumer willingness-to-pay for nutritional labeling. Data were collected from a random sample of 90 consumers selected from three supermarkets Dhanasiri, Cargill's Food City and Royal Garden Mall - located in Kandy. Market for nutritional labeling were identified by exploring data and a logit method of analysis was performed to identify the factors that influence the willingness-to-pay for nutritional information on food items. A significantly greater proportion of individuals in the age category 36 to 50 years, individuals with tertiary education, individuals with special dietary status and households with less than four members were willing to pay more for the nutritional labels. Logit analysis showed that gender, level of education and special dietary status have a significant positive effect and the household size has a significant negative effect on the willingness to pay for nutrition information. Accordingly, it could be stated that incorporation of a nutritional panel in the package would enhance the demand for food products and it would be an appropriate strategic task for the local food processors.
\end{abstract}

\section{Introduction}

Labeling is defined in the Federal Food, Drug and Cosmetic Act (FFDCA) in the United States of America (USA) as a written, printed, or graphic matter (i) upon any article or any of its containers or wrappers or (ii) accompanying such article. Labeling is a subset of packaging. Sellers need to label their products. The label may be a simple tag attached to the product or an elaborately designed graphic that is a part of the package.

\footnotetext{
* The authors are respectively, Final Year Undergraduate Student at the time the study was conducted, and Senior Lecturer in Agricultural Economics, University of Peradeniya.
} 
A label might carry only the brand name or a great deal of information (Kotler, 2001). According to the Food and Drug Administration (FDA) in the USA, a label is the primary point of contact between the producer and the purchaser and should be thought of as an integral part of the producer's marketing plan. It is not just a piece of paper stuck onto the container but should be an expression of a number of important decisions that have been made about marketing. According to the FDA (1998), a label should clearly and minimally state the name of the product, the net weight, the nutrition facts panel (nutritional label), the name and address of the manufacturer, and the brand name. These food labels have become increasingly complex, particularly as products move from the status of basic commodities to highly processed, value-added products (APO, 2002).

Nutritional labels can simplify the whole concept of healthy eating. It helps to keep track of the amount of fat and sugar, sodium and fiber, protein and carbohydrates. It also allows consumers to make an informed judgement of a product's overall value (APO, 2002). Therefore, the nutritional panel is a guide to a better diet and a healthier life (FDA, 1998). Consumers can use the nutritional label to make food choices according to the Dietary Guidelines developed by health experts who emphasize the importance of a well-balanced diet. According to the FDA (1998), nutrition information on food items allows consumers to, eat a variety of foods, maintain a healthy weight, choose a diet with low saturated fat, and cholesterol, choose a diet with plenty of vegetables, fruits, and grain products, use sugars only in moderation, use salt and sodium in moderation. Consumers can use health claims, which appear on the front of food packages, to identify foods with certain nutritional qualities related to risk factors and wellness. These are the claims about the relationship between a nutrient or a food and the risk of a disease or health-related condition (Brown and Schrader, 1990).

Nutritional labeling is found to affect the consumer purchase behavior significantly. Some evidence reveals that provision of nutrition information may allow consumers to switch consumption away from 'unhealthy' products in those food categories toward 'healthy' products in food categories more easily (Anderson and Zarkin, 1992). Improvements in nutrient intake of the population depend on the interaction of demand and supply forces in food markets. On the demand side, consumers' interest in the purchase of diets and products with improved nutritional profiles has a direct effect on nutrient intake. Consumers' ability to choose their diets depends partly on the quantity and quality of information available 
through a variety of sources, including nutrition panel food labels (Caswell and Padberg, 1999).

If the products are not labeled, consumers may not be fully aware of their nutrient content. Consumers must form their own beliefs about nutrient content based on advertising, public health messages, and their general knowledge of food science. However, this eventually leads to underestimates or overestimates of the content of particular nutrients in unlabeled food items (Anderson and Zarkin, 1992). Inherent in choosing food is a possible trade off between taste and the health consequences of nutrients. For example, pleasant tasting foods may contain nutrients such as fat or cholesterol which, when consumed, have negative marginal utilities because individuals believe they can improve their health by decreasing their intakes of these nutrients.

In Sri Lanka, the general requirements for foodstuffs are laid down in the Food Act, No. 26 of 1980 as amended. Compositional requirements for certain foods are laid down in the Food Regulations (Standards) 1989, as amended, the Food (Milk Standards) Regulations 1991, the Food (Iodisation of Salts) Regulations 1993, as corrected, and the Food (Bread Standards) Regulations 1994 (Munaweera, 2002). However, in Sri Lanka, inclusion of a nutritional label is not a legal requirement, hence; many products enter the market without a nutritional label. Given the liberalized environment in Sri Lanka, local food producers face immense competition from the imported products and from the products of multinational companies that have nutritional labels. Consumers have a better selection for their money. Therefore, it is imperative to study the impact of nutritional labeling on consumer buying behavior. Accordingly, local producers can decide whether they should put a nutritional label on their product or not. Given this background, this study was conducted with the objectives of identifying the market for nutritional labeling on food products (objects, objectives, occasions and occupants) and the factors that influence the willingness to pay for nutritional labeling on food items.

\section{Methodology}

A random sample of 90 consumers was selected from three supermarkets - Dhanasiri, Cargill's Food City and Royal Garden Mall located in Kandy. Primary data were collected from these customers by means of a pre-tested questionnaire. The questionnaire was designed to address the knowledge and attitudes toward diet, health, and nutrition labels. It consisted of several questions pertaining to the consumer's awareness on nutritional label information, the effect of nutrition labeling on buying 
decisions and willingness to pay for nutrition label information. Respondents were contacted at random while entering the supermarket's food sales section.

\section{Measurement of the Independent Variables}

There are no widely accepted theoretical or empirical guidelines for evaluating the factors that influence the willingness to pay for nutritional labeling on food items (Nayga, 1996). However, Guthrie et al., (1995) and Nayga (1996) approached the information provided by nutrition labels as a commodity, which consumers will continue to make use of as long as the benefits surpass the costs of label usage. This methodology initially proposed by Stigler (1961), specifically models the consumer's search for information which itself has been shown to be influenced by individual characteristics and many other characteristics. Working within this classification system, nutrition label use was modeled as a function of several major categories of variables including individual characteristics such as sex, age, education, household size, special diet status and monthly income.

Similarly, previous studies on nutritional labeling have incorporated some of the above variables and have explained their influence on consumer buying behaviour. Govindasamy and Italia
(1999) and Beus and Dunlap (1992) have concluded that females are more likely to use nutritional labeling than males and have shown that sex play a major role in buying behavior. Age is found to be significantly influencing the use of nutritional labeling where younger individuals are more likely to use nutritional labels than older individuals (Bender and Derby, 1992; Nayga, 1997; Govindasamy and Italia, 1999). Even though Nayga (1997) showed that income has a significant effect on the use of nutritional labeling, Caswell and Padberg (1999) revealed that income does not necessarily indicate a higher willingness to pay for nutritional information on food items. The level of education is considered to have a positive relationship with nutritional label use (Nayga, 1997; Govindasamy and Italia, 1999). Further, many researchers have concluded that special dietary status has a significant effect on the willingness to pay for nutritional information on food items (Caswell and Padberg, 1999; Govindasamy and Italia, 1999).

\section{Analytical Technique}

The logit regression analysis technique was selected as the analytical technique in this study because of its mathematical simplicity and asymptotic characteristics, which constrained the predicted probabilities to a range of zero to one. One important appeal of 
the logit model is that it transforms the problem of predicting probabilities within a $(0,1)$ interval to the problem of predicting the odds of an event's occurring within the range of the entire real line (Pindyck and Rubinfeld, 1981). The model as adopted by Pindyck and Rubinfeld (1981) could be represented by the following form.

$$
\begin{aligned}
& \mathrm{P}_{i}=F\left(Z_{i}\right)=F\left(\alpha+\beta \mathrm{X}_{i j}\right)=1 /\left[1+\mathrm{e}^{-Z i}\right] \\
& \text { where } \\
& \mathrm{F}\left(\mathrm{Z}_{i}\right)=\text { Value of the standard } \\
& \text { normal density } \\
& \text { function associated } \\
& \text { with each possible } \\
& \text { value of the underlying } \\
& \text { index } \mathrm{Z}_{i} \text {, } \\
& \mathrm{P}_{i} \quad=\text { Probability that an } \\
& \text { individual will make a } \\
& \text { certain choice, given } \\
& \mathrm{X}_{j}^{\prime} \mathrm{s} \text {, } \\
& \mathrm{E}=\text { The base of natural } \\
& \text { logarithm, } \\
& \mathrm{Z}_{i}=\text { Stimulus index for } i^{\text {th }} \\
& \text { observation, and } \\
& \mathrm{X}_{i j}=i^{\text {th }} \text { observation of the } j^{\text {th }} \\
& \text { independent variable. }
\end{aligned}
$$

So that;

$$
\log \left[\mathrm{P}_{\mathrm{i}} / 1-\mathrm{P}_{\mathrm{i}}\right]=\mathrm{Z}_{\mathrm{i}}=\alpha+\beta \mathrm{X}_{i j}
$$

The dependent variable in this regression equation is simply the logarithm of the odds that a particular choice is made and the $\mathrm{X}_{i j}$ is the $i^{\text {th }}$ observation of the $j^{\text {th }}$ independent variable.
The logit model used in this analysis assumes that the stimulus index defined above is a random variable, which predicts the probability of willingness to pay for nutritional labeling on food items. The model that was developed to determine the factors that influence the willingness to pay for nutritional labeling on food items is as follows.

$$
\begin{aligned}
\mathrm{Y} & =\beta_{0}+\beta_{1} \mathrm{X}_{1}+\beta_{2} \mathrm{X}_{2}+\beta_{3} \mathrm{X}_{3} \\
& +\beta_{4} \mathrm{X}_{4}+\beta_{5} \mathrm{X}_{5}+\beta_{6} \mathrm{X}_{6} \\
& +\beta_{7} \mathrm{X}_{7}+\mu_{\mathrm{I}}
\end{aligned}
$$

where

$$
\begin{aligned}
\mathrm{Y}_{\mathrm{i}}= & 1 \text { for consumers who are } \\
& \text { willing to pay extra for } \\
& \text { nutritional labeling } \\
\mathrm{Y}_{\mathrm{i}}= & \begin{array}{l}
\text { for consumers who are not } \\
\text { willing to pay extra for }
\end{array} \\
& \text { nutritional labeling } \\
\mathrm{X}_{1}= & \text { Gender } \\
\mathrm{X}_{2}= & \text { Age in years } \\
\mathrm{X}_{3}= & \text { Level of education in years } \\
\mathrm{X}_{4}= & \text { Household size } \\
\mathrm{X}_{5}= & \text { Nutritional education } \\
\mathrm{X}_{6}= & \text { Special dietary status } \\
\mathrm{X}_{7}= & \text { Income in Rupees } \\
\mu_{\mathrm{I}}= & \text { Error term }
\end{aligned}
$$

\section{Results and Discussion}

\section{What does the Market Buy? (Objects)}

Among the respondents, $86 \%$ had an awareness about the nutritional labels on food products, while $14 \%$ did not have an awareness about nutritional labels. This 
particular finding suggests that there is a consumer propensity to read nutrition labels and it could change their purchasing behavior, which ultimately reflects their relative valuation of taste versus health.

Out of the 90 respondents, $77.8 \%$ considered that nutritional information on food items are vital for their purchasing decisions. Among the other factors considered during food shopping such as price, quality, packaging, label, and brand, the highest level of importance was attached to nutritional labeling on food products. Twenty five percent of the respondents stated that they always read the nutrition labels when purchasing a food item and $62 \%$ said they sometimes read it. Only $2 \%$ said that they never look at the label. This particular finding suggests that printed nutrition information is an important source of "new knowledge" that consumers use in purchasing. Out of the total number of 90 respondents $52.2 \%$ were willing to pay something additional for products with nutrition information and $47.8 \%$ were not willing to pay anything additional.

\section{Why does the Market Buy? (Objectives)}

Sixty five percent of the respondents interviewed indicated that health consciousness is the main reason to buy products with nutritional labeling. Ten percent were willing to buy because it attaches a higher quality to the product. Twenty five percent were buying the product because of the quality as well as health consciousness.

\section{When Does the Market Buy? (Occasions)}

Of the total number of respondents, 27 were undergoing special dietary status such as diabetics or heart diseases, or were vegetarian. Eighty five per cent of them who were on special diets were willing to pay for nutritional labeling while the others were not willing to pay. A possible explanation for this might be that shoppers on these diets are more likely to check for nutrition information, which has an impact on their health and wellness.

\section{How does the Market Buy? (Operations)}

Additional willingness to pay (AWP) for three different product categories was obtained by indicating the prevailing average price of these products in the supermarkets as the base value. Statistically, there is a significant difference between the additional willingness to pay values obtained for each product category. The highest AWP was with the oilbased products (Table 1). This reflects that the consumers are more willing to pay for nutrition information on oil based products. 
Table 1: Additional Willingness to Pay for Nutritional Labeling

\begin{tabular}{lcc}
\hline \multicolumn{1}{c}{ Product } & Average Price (Rs.) & AWP \\
\hline Processed meat products & 120 & 25.75 \\
Oil based products & 90 & 30.25 \\
Fruit syrups & 75 & 12.73 \\
\hline
\end{tabular}

Table 2: Willingness to Pay by Age Group

\begin{tabular}{lccc}
\hline $\begin{array}{c}\text { Age group } \\
\text { (Years) }\end{array}$ & No. of observations & $\begin{array}{c}\text { Willing to } \\
\text { pay }\end{array}$ & $\begin{array}{c}\text { Willing to pay } \\
(\%)\end{array}$ \\
\hline$>65$ & 5 & 1 & 20.0 \\
51 to 65 & 26 & 15 & 57.7 \\
36 to 50 & 35 & 26 & 74.3 \\
$<36$ & 24 & 4 & 16.7 \\
\hline
\end{tabular}

Who Constitutes the Market? Willingness to Pay by Gender (Occupants)

Of the total number of

\section{Willingness to Pay by Age Group}

Of the 90 respondents, 35 were in the 36-50 year age group and of those $74.3 \%$ indicated that they are willing to pay for nutritional information on food items. Only 5 respondents were in the over 65-year age group, and of those 20\% revealed that they are willing to pay for nutritional information (Table 2). Chi square test results revealed that the relationship between age and the willingness to pay is statistically significant at a probability level of 0.05 . Similarly, Govindasamy and Italia (1999) have also shown that the middle age respondents are more likely to pay for nutrition information, while the older and younger generations are less likely to pay. respondents, 43 were males and 47 were females. Of the females, 20 were willing to pay for nutrition information, which accounts for $57.4 \%$. Males were less likely to pay for nutrition information (Table 3). Chi-square test result revealed that the relationship between gender and the willingness to pay is statistically significant at a probability level of 0.05 . This result suggests that females, their families food gatekeeper's, have a large share of the responsibility for their families' health and are willing to pay more for nutrition information.

\section{Willingness to Pay by Income}

Out of the total 90 respondents 49 were in the income category Rs. 10,000 to Rs. 20,000 and of those $55.1 \%$ were willing to pay for 
Table 3: Willingness to Pay by Gender

\begin{tabular}{lccc}
\hline \multicolumn{1}{c}{ Gender } & $\begin{array}{c}\text { No. of } \\
\text { observations }\end{array}$ & Willing to pay & $\begin{array}{c}\text { Willing to pay } \\
(\%)\end{array}$ \\
\hline Male & 43 & 20 & 46.5 \\
Female & 47 & 27 & 57.4 \\
\hline
\end{tabular}

Table 4: Willingness to Pay by Income

\begin{tabular}{lccc}
\hline $\begin{array}{c}\text { Monthly } \\
\text { average income } \\
\text { (Rs.) }\end{array}$ & No. of observations & Willing to pay & $\begin{array}{c}\text { Willing to pay } \\
(\%)\end{array}$ \\
\hline$<10,000$ & 24 & 9 & 37.50 \\
$10,000-20,000$ & 49 & 27 & 55.10 \\
$>20,000$ & 17 & 9 & 52.94 \\
\hline
\end{tabular}

Table 5: Willingness to Pay by Household Size

\begin{tabular}{lccc}
\hline Household size & No. of observations & Willing to pay & $\begin{array}{c}\text { Willing to pay } \\
(\%)\end{array}$ \\
\hline$\leq 4$ members & 52 & 10 & 19.2 \\
$>4$ members & 38 & 28 & 73.7 \\
\hline
\end{tabular}

nutritional information on food items. Seventeen individuals were in the income category above Rs.20,000 and of those $37.5 \%$ were willing to pay for nutritional labeling (Table 4). However, there was no statistical significance between income and the willingness to pay for nutrition information on food items.

\section{Willingness to pay by Household} Size

Of the total number of respondents, 38 households had less than 4 members and of those $73.7 \%$ were willing to pay for nutrition information. However, only $19 \%$ of the households with more than 4 members revealed that they are willing to pay for nutrition information (Table 5). Chi-square test results revealed that there is a significant relationship between household size and the willingness to pay.

\section{Willingness to Pay by Education Level}

Of the total, 52 respondents had a university degree and of those $62 \%$ indicated that they are willing to pay for nutritional labeling. Thirty-two have had secondary education and of those $37.5 \%$ were willing to pay for nutrition information provided on the food labels (Table 6). 
Table 6: Willingness to Pay by Education Level

\begin{tabular}{lccc}
\hline \multicolumn{1}{c}{ Level of education } & $\begin{array}{c}\text { No. of } \\
\text { observations }\end{array}$ & $\begin{array}{c}\text { Willing to } \\
\text { pay }\end{array}$ & $\begin{array}{c}\text { Willing to pay } \\
(\%)\end{array}$ \\
\hline No Secondary education & 6 & 1 & 16.7 \\
Up to advanced level & 32 & 12 & 37.5 \\
At least a degree & 52 & 32 & 61.5 \\
\hline
\end{tabular}

Six respondents have had no secondary education and of those $17 \%$ indicated that they are willing to pay for nutrition information. Chisquare test results revealed that there is a statistical significance between educational attainment and the willingness to pay for nutritional labeling.

\section{Factors Influencing the Willingness to Pay for Nutritional Labeling}

Logit analysis was used to analyze the factors that influence the willingness to pay for nutritional labeling on food items. Of the seven variables considered; gender, education, special dietary status and household size were significant at a probability level of 0.05 (Table 7).

Gender has a positive and a significant effect on the willingness to pay for nutritional labels. Females are more likely to pay for nutritional labeling. This finding is also consistent with the findings of Nayga (1997) and Govindasamy and Italia (1999) where they showed that males are less likely to use nutritional labels than females. Although the role of women in the household has been redefined over the years, still women are the main meal preparers and families' food gatekeepers. They have a responsibility and intrinsic interest in providing safe and wholesome food for their families. Conversely, males are more likely to purchase food only for themselves and more likely to purchase only a few items at a time rather than do the large weekly shopping. Nutrition educators face the challenge of designing programs that encourage males to increase their use of the nutrition information available on food labels.

Above results also show that the level of education has a positive and significant effect on the willingness to pay for nutritional labeling on food items. Those with higher education appear to be more capable of interpreting the information provided on nutrition labels and incorporating that information into a healthy diet. Similarly, studies carried out by Nayga (1997) and Govindasamy and Italia (1999) have revealed that education level has a significant effect on the nutritional label usage. 
Table 7: Results of the Logit Analysis

\begin{tabular}{lllll}
\hline \multicolumn{1}{c}{$\begin{array}{l}\text { Independent } \\
\text { Variable }\end{array}$} & Coefficient & Standard error & $t$-ratio & Significance \\
\hline Gender & 1.6244 & 0.79308 & 2.0482 & $*$ \\
Age & $-0.11614 \mathrm{E}-01$ & $0.28596 \mathrm{E}-01$ & -0.40614 & $\mathrm{NS}$ \\
Income & $-0.17702 \mathrm{E}-04$ & $0.62597 \mathrm{E}-04$ & -0.28279 & $\mathrm{NS}$ \\
Education & 0.22407 & $0.88840 \mathrm{E}-01$ & 2.5222 & $*$ \\
$\begin{array}{l}\text { Nutrition } \\
\text { education }\end{array}$ & 1.4048 & 1.0036 & 1.3998 & $\mathrm{NS}$ \\
$\begin{array}{l}\text { Special dietary } \\
\text { status }\end{array}$ & 3.1062 & 0.98787 & 3.1444 & $*$ \\
Household size & -0.61515 & 0.29505 & -2.0849 & $*$ \\
\hline
\end{tabular}

*- Significant at a probability level of 0.05

NS - Not Significant

Maddala $R^{2}-0.4885$

Cragg-Uhler $\mathrm{R}^{2}-0.65307$

McFadden $\mathrm{R}^{2}-0.48638$

Chow ${ }^{2}-0.52414$

The variable dietary status, which was used to represent the individual's current health status, has a positive effect on the willingness to pay for nutrition information. This finding is also consistent with the findings of Caswell and Padberg (1999), and Govindasamy and Italia (1999), where they showed that health status has a positive influence on food label usage.

Accordingly, it could be suggested that those who have current health concerns appear to perceive greater benefit from label use, assuming they are able to use the information to make healthy food choices. This emphasizes the role that a healthy diet plays on a person's future health, which could encourage the willingness to pay for nutrition labels.

The variable household size was found to be negatively influencing the willingness to pay for nutrition information. A possible reason is that large households are willing to pay less for nutritional labeling than the small households. This may be due to the burden of heavy expenditures for daily needs and wants. This is also consistent with the findings of Govindasamy and Italia (1999) where they showed that as the household size increases the importance of nutritional labels decreases significantly. 


\section{Conclusions}

This study shows that consumers use nutritional labeling when making a purchasing decision and that it is especially because of health consciousness. A majority of the respondents revealed that they are willing to pay something additional for the nutritional information provided on food items. Of those who are willing to pay something additional, a greater proportion was in the age category 36 to 50 years, have had tertiary education and the households had less than 4 members. Similarly, respondents who were on special dietary status such as diabetics, or heart disease, or were vegetarian have also revealed that they are willing to pay more for nutritional labeling. Further, logit analysis showed that gender, level of education and special dietary status have a significant positive effect and the household size has a significant negative effect on the willingness to pay for nutrition information. Accordingly, it could be stated that incorporation of a nutritional panel on the package would enhance the demand for the local food products and it would be an appropriate strategic task for the local food processors. Thereby, these local producers could compete with the other products with nutritional labels and also it would be an ideal strategy in penetrating export markets where the nutritional panel is a legal requirement.

\section{References}

Asian Productivity Organization. (2002). Food Standards and Labeling Systems in Asia and the Pacific. Tokyo:Asian Productivity Organization.

Anderson, D.W.and G.A. Zarkin. (1992). Consumer and Producer Responses to Nutritional Label Changes. American Journal of Agriculture Economics. 74:1202-1207.

Bender, M.M. and B.M. Derby. (1992). Prevalence of Reading Nutrition Information and Ingredient Information on Food Labels among Adult Americans. Journal of Nutrition Education. 24:292297.

Beus, C. and R. Dunlap. (1992). Understanding Public Concerns about Pesticides: An Empirical Examination. Journal of Consumer Affairs. 25:260-275.

Brown, D.J.and L.F. Schrader. (1990). Cholesterol Information and Shell Egg Consumption. American Journal of Agricultural Economics. 72:548-555. 
Caswell, J.A. and D.I. Padberg. (1999). Toward a More Comprehensive Theory of Food Labels. American Journal of Agricultural Economics. 74:460-468.

FDA. (1998). An FDA Guide to Dietary Supplements. American Journal of Agricultural Economics. 32:28-35.

Govindasamy, R.and J. Italia. (1999). Evaluating Consumer Usage of Nutritional Labeling: The Influence of Socio-Economic Characteristics. Journal of Nutritional Education. 4:370375.

Guthrie, J.F., J.F Jonathan, E.C. Linda and W.Susan. (1995). Who Uses Nutritional labeling, and What Effect does Label Use have on Diet Quality?. Journal of Nutritional Education. 27(4):163-172.

Kotler, P. (2001). Marketing Management. $2^{\text {nd }}$ Ed. Boston: Irwin, McGraw-Hill.

Munaweera, R.D. (2002). Sri Lanka. In Food Standards and Labeling Systems in Asia and the Pacific. Tokyo:Asian Productivity Organization. 186-194.
Nayga, R.M. (1996). Determinants of Consumers' Use of Nutritional information on Food Packages. Journal of Agricultural and Applied Economics. 28(2):303-312.

Nayga, R.M. (1997). Impact of Socio-Demographic Factors on Perceived Importance of Nutrition in Food Shopping. Journal of Consumer Affairs. 31(1):1-9.

Pindyck, R.S. and D.L. Rubinfeld. (1981). Econometric Models and Economic Forecasts. $2^{\text {nd }}$ ed.Singapore: McGraw-Hill.

Stigler, G.J. (1961). The Economics of Information. Journal of Political Economy. 69(3):213222. 